\title{
OBSOLESCÊNCIA PROGRAMADA, CONSUMISMO E FUNÇÃO SOCIAL DO DESIGN
}

Lia Assumpção

FAU - Universidade de São Paulo

liaassumpcao@usp.br

Denise Dantas

FAU - Universidade de São Paulo

dedantas@usp.br

Resumo: Este artigo faz uma reflexão sobre a obsolescência programada e o papel do design no desenvolvimento de produtos no contexto contemporâneo da escassez de recursos e alta geração de lixo, abordando conceitos como o consumismo e a função social do design. Para isso, usa como referência Papanek (1971, 1998), Bauman (2008), Krippendorff (2000) e Manzini (2008), comparando seus conceitos a respeito do consumismo, design e obsolescência programada, com segmentos de produtos eletrônicos e de largo consumo na situação atual. Para finalizar, apresenta iniciativas de indústrias que buscam caminhos no design para melhorar e minimizar os efeitos do descarte no planeta.

Palavras-chave: design e sustentabilidade, obsolescência programada, projeto de produto, função social do design. 


\section{INTRODUÇÃO}

A Organização das Nações Unidas (ONU), em seu relatório Waste crime - waste risks (2015), divulgou que o lixo eletrônico gerado no mundo em 2014 foi de 41,8 milhões de toneladas e estima que esse número suba para 50 milhões em 2018. O Brasil foi responsável por 1,4 milhão de toneladas em 2014, aponta outro relatório da mesma entidade, Gestão Sustentável de Resíduos de Equipamentos Eléctricos e Eletrônicos na América Latina (2015), com dados sobre a gestão do lixo eletrônico na Argentina, Bolívia, Brasil, Chile, Colômbia, Equador, Paraguai, Uruguai e Venezuela. O documento coloca o Brasil em segundo lugar no ranking dos geradores de lixo eletrônico, perdendo apenas para os Estados Unidos, que produziu pouco mais de 7 milhões de toneladas de lixo no mesmo ano, segundo o mapeamento feito pela Step, iniciativa da ONU para mapear o lixo eletrônico no mundo.

Uma pesquisa sobre ciclo de vida de aparelhos eletrônicos, realizada pelo Instituto Brasileiro de Defesa do Consumidor (Idec) e pelo Instituto de Pesquisa Market Analysis $(2013)^{1}$, demonstrou a satisfação dos consumidores no que diz respeito ao desempenho e durabilidade dos produtos eletroeletrônicos. Os dados obtidos pela pesquisa colocaram a durabilidade planejadamente reduzida dos aparelhos como indutor das vendas. Correlacionando o tempo de posse dos aparelhos com o número de problemas relatados no período pesquisado, o resultado é que, em média, a cada cinco anos, $51,6 \%$ de todos os computadores e $42,3 \%$ de todos os celulares do país apresentarão algum defeito e na maior parte das vezes serão trocados e não consertados. João Paulo Amaral, pesquisador do Idec, considera que:

"Existe o que poderíamos qualificar como uma assimilação conformada do consumidor frente às estratégias da indústria e da propaganda, já que ele percebe 'em abstrato' que os aparelhos deveriam durar mais, mas está satisfeito com a durabilidade e desempenho de seu aparelho." (IDEC, 2016).
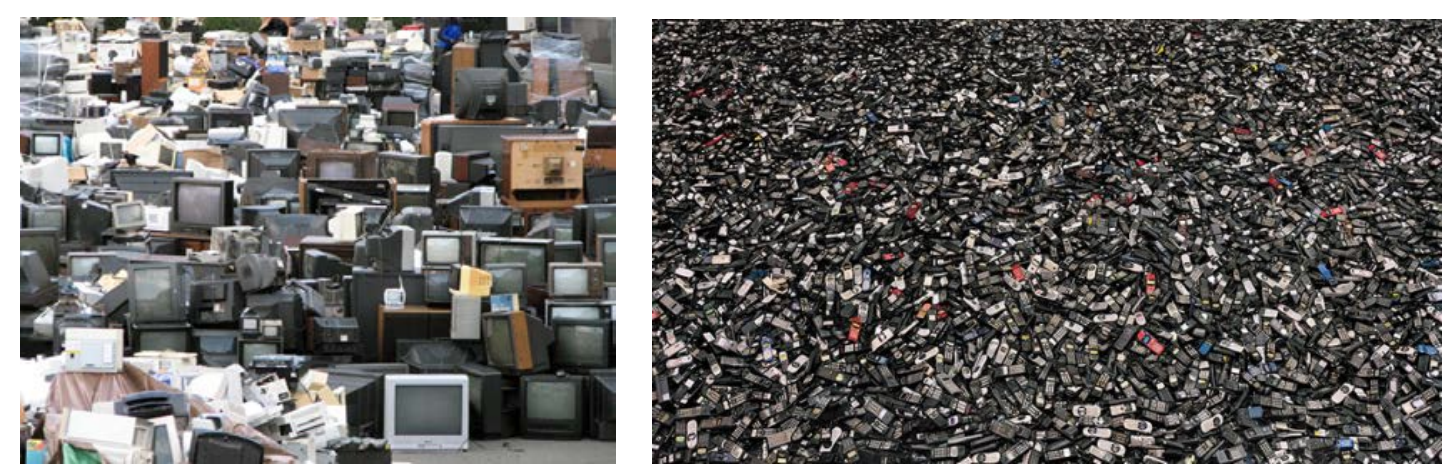

Imagens que ilustram locais de de descarte de lixo eletrônico

Fonte: http://www.muycomputerpro.com e http://www.fatonews.com.br

\footnotetext{
${ }^{1}$ Foram entrevistados, por telefone, 806 homens e mulheres, de 18 a 69 anos, de diferentes classes sociais das seguintes cidades: Belo Horizonte (MG), Brasília (DF), Curitiba (PR), Goiânia (GO), Porto Alegre (RS), Recife (PE), Rio de Janeiro (RJ), Salvador (BA) e São Paulo (SP). O número de entrevistados em cada capital foi proporcional à população de cada capital. O levantamento foi feito entre agosto e outubro de 2013. A margem de erro é de 3,5\% para mais ou para menos. Disponível em <http://www.idec.org.br/consultas/testes-e-pesquisas/em-cinco-anos-metade-doscomputadores-apresentara-algum-defeito > Acesso em 10.05.16.
} 
Neste contexto, e tendo como base teórica os tipos de obsolescência listados por Victor Papanek em 1971, a sociedade de consumidores descrita por Zygmunt Bauman (2008), as ideias do papel social do design de Klaus Krippendorff (2000) e as propostas de desenvolvimento de produto de Ezio Manzini (2008), este artigo reflete sobre as práticas projetuais do design e suas possíveis contribuições para a redução dos danos causados pela obsolescência programada.

Para Sevcenko (2001), as inovações tecnológicas modificam todo o aparato tecnológico vigente em períodos cada vez mais curtos, reconfigurando o universo de possibilidades e de expectativas "tornando-o cada vez mais imprevisível, irresistível e incompreensível" (p. 16). Numa sociedade marcada pela velocidade (de transformações e de troca de informações), a questão que se coloca diz respeito às consequências que estas transformações acarretam na sociedade, e o papel do design na melhoria deste cenário. "A crítica, portanto, é o modo de a sociedade dialogar com as inovações, ponderando sobre seu impacto, avaliando seus efeitos e perscrutando seus desdobramentos" (SEVCENKO, 2000, p. 17).

\section{DESENVOLVIMENTO}

Esta pesquisa bibliográfica se baseou na leitura e comparação dos conceitos de Papanek (1971). Para o autor, existem três tipos de obsolescência:

a) A tecnológica, que se dá quando se descobre uma maneira melhor ou mais elegante de fazer as coisas;

b) A material, quando o produto se desgasta naturalmente;

c) A artificial, quando o desgaste acontece num intervalo de tempo previsível e se dá sobretudo por duas razões: pela escolha de materiais ou acabamentos menos duráveis ou porque partes significativas do produto não são substituíveis ou reparáveis. Para o autor, esta é a "sentença de morte" de um produto.

Neste sentido, interessa neste artigo o último tipo, conhecido como obsolescência programada ou planejada, pois, como descrito acima, determina (e reduz) o tempo de uso de um objeto, tornando-o descartável. Talvez o maior símbolo da obsolescência programada atualmente seja o telefone celular. Ele é um exemplo de bem de consumo que tem preço de bem durável, mas é tratado como descartável. Em 2014 foram vendidos 70,3 milhões de celulares, segundo o relatório Panorâmico e Desempenho Setorial (2015), da Associação Brasileira da Indústria Elétrica e Eletrônica (ABINEE).

Para Papanek (1971), quando as pessoas são convencidas a jogar fora seus carros antes de se desgastarem, suas roupas, para estar de acordo com as tendências da moda, ou seus aparelhos eletroeletrônicos, sempre que uma nova função é agregada ou um novo modelo lançado, corre-se o risco de considerar tudo obsoleto. Tornando descartáveis móveis, veículos, roupas e aparelhos eletrônicos, podemos passar a sentir que as relações pessoais também são descartáveis e, numa escala global, países e subcontinentes inteiros podem passar também a ser descartáveis. Não valorizamos 0 que jogamos fora e, quando projetamos coisas para serem descartadas, exercitamos um 
design descuidado no que diz respeito a fatores de segurança, ou mesmo à ideia de alienação ou efemeridade das coisas. A pronta aceitação dos consumidores com relação a qualquer coisa nova ou diferente estimulou a indústria e, "a miscigenação da tecnologia e da aceleração artificial dos desejos do consumidor, fizeram nascer a sombria dupla estilo e obsolescência" (PAPANEK, 1971, p. 87).

O receio de Papanek se consolidou no que Bauman (2008) chama de "sociedade de consumidores", que é o ambiente existencial em que vivemos hoje, e que se distingue por uma reconstrução das relações humanas a partir do padrão e, à semelhança, das relações entre consumidores e os objetos de consumo. Para o autor, essa maneira de se relacionar é um dos "danos colaterais" ou "baixas colaterais" da sociedade de consumidores, assim como a obsolescência programada:

\footnotetext{
"Entre as maneiras com que o consumidor enfrenta a insatisfação, a principal é descartar os objetos que a causam. A sociedade de consumidores desvaloriza a durabilidade, igualando 'velho' a 'defasado', impróprio para continuar sendo utilizado e destinado à lata do lixo. A sociedade de consumidores é impensável sem uma florescente indústria de remoção de lixo. Não se espera dos consumidores que jurem lealdade aos objetos que obtêm com a intenção de consumir." (BAUMAN, 2008, p. 31)
}

A diferença entre consumo e consumismo, segundo Bauman (2008), está na intensidade: enquanto o primeiro ocupa setores pontuais da vida das pessoas como uma atividade trivial, o segundo exerce papel central na sociedade. Em suas palavras, "de uma maneira distinta do consumo, que é basicamente uma característica e uma ocupação dos seres humanos como indivíduos, o consumismo é um atributo da sociedade" (p. 41) e traz em suas características uma "obsolescência embutida" dos bens de consumo, pois, "a sociedade de consumidores talvez seja a única na história humana a prometer felicidade na vida terrena, aqui e agora e a cada 'agora' sucessivo" (p. 60), uma felicidade instantânea a cada compra que se perpetua no eterno comprar que, em verdade, não satisfaz, pois não traz a felicidade almejada. Para atender a todas as necessidades, impulsos, compulsões e vícios, e para manter vivas e renovar as expectativas de felicidade já descreditadas e descartadas, a economia consumista tem de se basear no excesso e no desperdício, encurtando o caminho da loja à lata de lixo. Nesse sentido, conceitos do vocabulário dos advogados como "danos colaterais" ou "vitimas colaterais" estão atualmente sendo empregados para alegar uma falta de intencionalidade nas ações. Trazendo esta ideia para o discurso da obsolescência, a questão controversa é se os danos ambientais acarretados por ela são realmente "impossíveis de prever" ou "impossíveis de evitar intencionalmente", uma vez que os objetos são feitos intencionalmente para durar pouco tempo, tornando-se lixo, na maior parte das vezes. Como destacou Bauman (2008), existem razões para suspeitar que o argumento "falta de intencionalidade" é empregado apenas para negar a "cegueira ética" dos processos produtivos na sociedade de consumidores.

Em 2010, entrou em vigor no Brasil a Política Nacional de Resíduos Sólidos (PNRS), definida como um "instrumento de desenvolvimento econômico e social caracterizado por um conjunto de ações, procedimentos e meios destinados a viabilizar a coleta e a restituição dos resíduos sólidos ao setor empresarial, para reaproveitamento, em seu ciclo ou em outros ciclos produtivos, ou outra destinação final ambientalmente adequada". A lei determina diretrizes para a gestão integrada e o gerenciamento de resíduos sólidos no país, responsabilizando produtores e 
consumidores pelos materiais produzidos e descartados. Merecem destaque algumas definições e determinações tratadas no capítulo 2 deste documento:

- "destinação final ambientalmente adequada: reutilização, reciclagem, compostagem, recuperação e aproveitamento energético de modo a evitar danos ou riscos à saúde pública e à segurança e a minimizar os impactos ambientais;

- logística reversa: instrumento de desenvolvimento econômico e social caracterizado por um conjunto de ações, procedimentos e meios destinados a viabilizar a coleta e a restituição dos resíduos sólidos ao setor empresarial, para reaproveitamento, em seu ciclo ou em outros ciclos produtivos, ou outra destinação final ambientalmente adequada;

- padrões sustentáveis de produção e consumo: produção e consumo de bens e serviços de forma a atender as necessidades das atuais gerações e permitir melhores condições de vida, sem comprometer a qualidade ambiental e o atendimento das necessidades das gerações futuras;

- responsabilidade compartilhada pelo ciclo de vida dos produtos: conjunto de atribuições individualizadas e encadeadas dos fabricantes, importadores, distribuidores e comerciantes, dos consumidores e dos titulares dos serviços públicos de limpeza urbana e de manejo dos resíduos sólidos, para minimizar o volume de resíduos sólidos e rejeitos gerados, bem como para reduzir os impactos causados à saúde humana e à qualidade ambiental decorrentes do ciclo de vida dos produtos, nos termos desta Lei." (MINISTÉRIO DO MEIO AMBIENTE, 2016)

Para contemplar a lei, o projeto do produto precisa ser pensado levando em consideração todas as etapas do seu ciclo de vida. Se as etapas iniciais do desenvolvimento de um produto estiverem alinhadas com a parte final de seu ciclo, mais fácil será cumprir as responsabilidades listadas na lei. Para Manzini (2008), a etapa de desenvolvimento de produtos de design deve contemplar soluções para promover uma abordagem sistêmica que considere planejamento, produção execução, uso e descarte final.

Considerando a política nacional de resíduos sólidos e as questões abordadas sobre a relação do consumo excessivo com a obsolescência programada, enxerga-se uma ponte entre a ação projetual do designer e o resultado dos produtos que vão para o mercado. Desta forma, questiona-se neste trabalho como a função social do profissional de design está atrelada aos fatos mencionados. Segundo Margolin (2004), a função social do design tem como objetivo a satisfação das necessidades humanas, o que contribui para o bem-estar humano e se diferencia do design de mercado, que visa criar produtos para venda. Para Redig (2011) não existe design que não seja social, uma vez que ele é sempre feito para a sociedade. "O que seria design social? Design comercial? Design comercial que não for dirigido às necessidades da sociedade não é design." (REDIG, 2001, p. 92-93). Braga (2011) introduz seu livro O papel social do design gráfico lançando a ideia de que "em teoria, todo profissional consciente de seu papel ao exercer sua função social de maneira ética e de modo eficaz contribui para que a sociedade de que faz parte se desenvolva em harmonia." (BRAGA, 2011, p. 10 -11) 
Na mesma direção, Krippendorf (2000) defende que a função social, na sua íntima relação com o consumismo e com o impacto ambiental negativo da extração incessante e acelerada de recursos naturais, é extremamente importante de ser avaliada, pois o design prescinde da cooperação entre pessoas e está interessado no que pode ser alterado para a realização de futuros desejáveis. O design deve propor mudanças nas práticas sociais, questionar o que outros discursos dizem ser impossível; deve inspirar outros a levar adiante suas ideias, numa espécie de rede em que as virtudes do design são difundidas pela propagação de suas propostas. "Design é a defesa de uma causa. Onde as pessoas falam sobre design, ele torna-se político" (KRIPPENDORF, 2000, p. 94).

Enquanto o consumismo se alimenta e é alimentado pela obsolescência programada, a função social do design devolve um pouco de ética ao processo, pois situa o desenvolvimento de produtos em um mundo com excesso de lixo. Quando um pensamento sistêmico integra as demandas de um projeto de produto, os "danos colaterais" são reduzidos.

Um exemplo de desenvolvimento de projeto que considera todas as etapas do ciclo de vida de um produto e a responsabilidade ambiental é o carro da BMW. Segundo o site da empresa (em português), seus carros são feitos de maneira a serem recebidos e reciclados no final de seu ciclo de vida. Assegura-se que os veículos poderão ser rápida e eficientemente reciclados, pois são fabricados com uma gama reduzida de materiais, montados de maneira a serem separados; além disso, a empresa conta com o envolvimento de empresas especializadas em reciclagem de veículos em fim de vida. "As quatro etapas de processamento ecológico de veículos em fim de vida são: entrega controlada, pré-tratamento, desmontagem e reciclagem do veículo residual." (BMW, 2016). No site também está anunciado o engajamento da empresa com a implantação da Política Nacional de Resíduos Sólidos, que futuramente exigirá que $85 \%$ do peso de um veículo em fim de vida devam ser reutilizados na forma atual dos componentes, ou como material para novas peças.

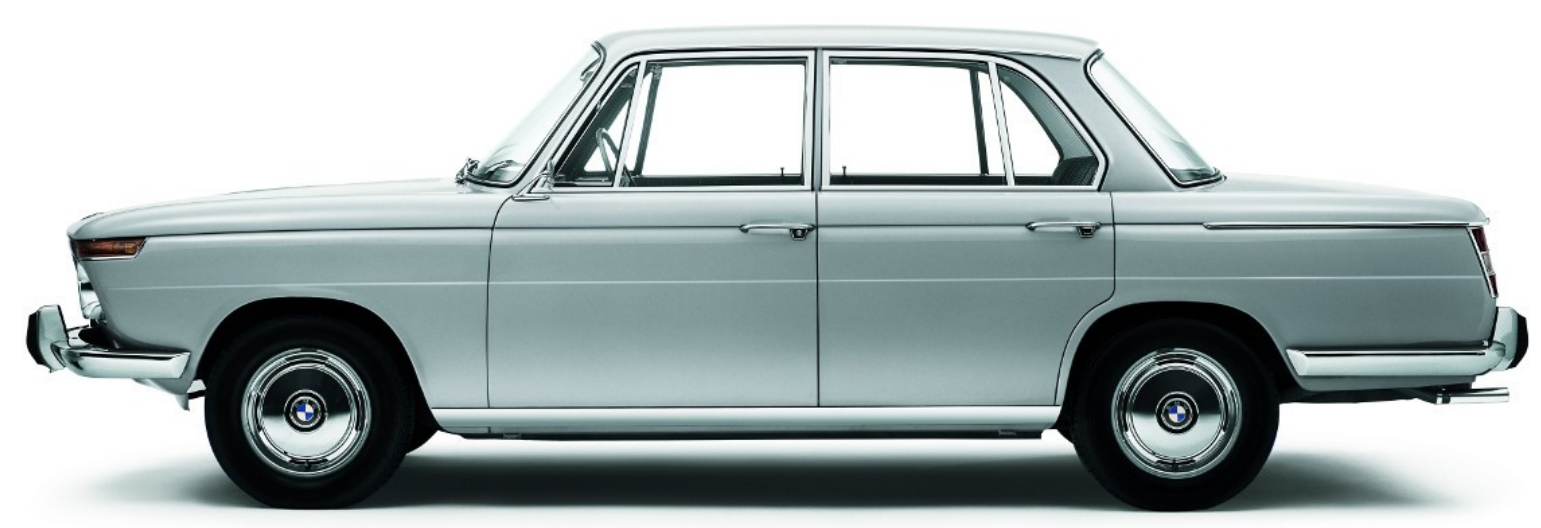




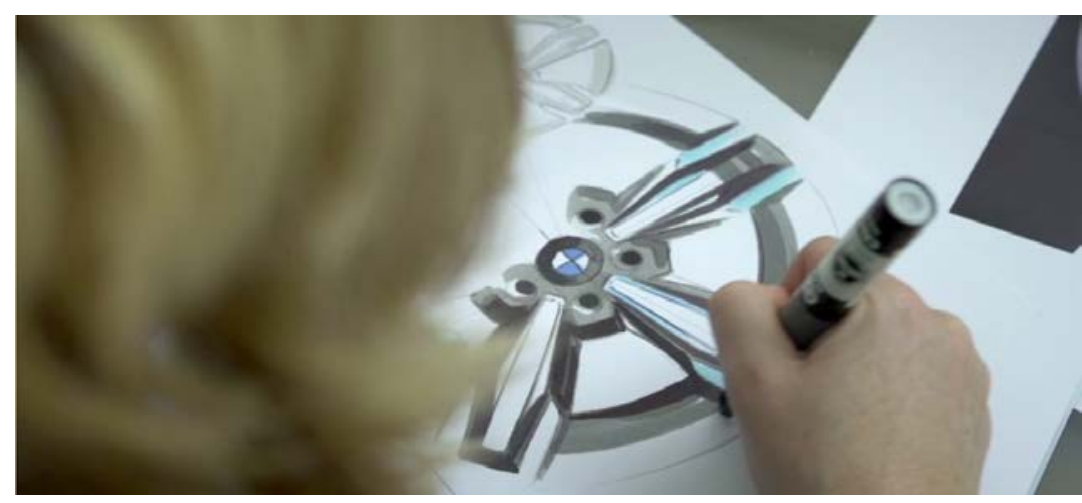

Imagens extraídas do site da BMW

Fonte: www.bmw.pt

“Essa meta foi, há muito, alcançada para as peças em metal. O vidro e muitos dos plásticos já podem ser economicamente recuperados. O BMW Group representou um papel vital neste processo criando novas técnicas. Os motores desmontados por técnicos especializados podem ser recondicionados e reutilizados para o seu propósito original, como uma forma de reciclagem de topo. Após desmontagem, os veículos residuais são enviados para uma empresa de trituração. Estas instalações cortam a carroçaria residual em peças do tamanho de uma mão e separam-nas. Plásticos, têxteis, ferro e metais nãoferrosos são reutilizados." (BMW, 2016)

É necessária uma conscientização geral do mercado, e novas medidas devem ser avaliadas no desenvolvimento de produtos. Como foi visto no exemplo da BMW, é possível uma empresa seguir a sua função social, adotando uma maior responsabilidade ambiental no desenvolvimento de seus produtos.

\section{CONSIDERAÇÕES FINAIS}

Num ciclo virtuoso, a obsolescência programada se alimenta do consumismo e é, ao mesmo tempo, consequência dele. $O$ design entra nesse ciclo como ator principal na geração de desejos e necessidades constantes e incansáveis nos consumidores. A função social do design trata de integrantes da sociedade, não somente de consumidores, e projetos de produto que levem isso em conta remarão contra o consumismo e a obsolescência programada.

\footnotetext{
"Apesar de uma situação econômica que ameaça, os designers devem contribuir para as reais necessidades humanas e sociais. Isto exigirá grandes sacrifícios e um trabalho muito mais inovador. A alternativa é o caos." (PAPANEK, 1971, p. 38)
}

Como ilustra o exemplo da BMW, é possível pensar na logística reversa como algo lucrativo, pois, se as peças usadas puderem ser reaproveitadas novamente no início ou em alguma outra etapa do processo de fabricação dos carros, haverá uma economia de novos recursos. As limitações de hoje podem gerar ideias inovadoras que proponham novos usos dos artefatos e uma mudança na sociedade.

O papel social do design, portanto, poderá ser evidenciado quando os designers pensarem os produtos para serem desmontados, como indicava Papanek e como está fazendo a BMW. Este caminho, entretanto, não dá conta de resolver o consumismo, 
principal fonte deste problema. Longe de atacar o problema no seu cerne, o Design para a Desmontagem apenas minimiza os impactos ambientais do descarte dos produtos ao permitir melhor reciclabilidade de seus componentes. Entretanto, não garante uma maior vida útil ao produto ou um consumo mais consciente.

Eticamente, produtos pensados para quebrar, como são conhecidos, acabam por se tornar um design antiético, desconsiderando todos os aspectos acima descritos. Estes, sim, incentivam o consumismo, ao estabelecerem uma configuração formal que dificulte o conserto ou até o impossibilite, de modo que tudo se torna extremamente descartável. Nesse sentido, o design perde sua função social, contradizendo o dito por Redig (2011), uma vez que a intencionalidade do fato não deixa dúvidas sobre seus preceitos e efeitos.

\section{REFERÊNCIAS}

BAUMAN, Zygmunt. Vida para consumo: a transformação das pessoas em mercadorias. Rio de Janeiro: Zahar, 2008.

BMW. Reciclagem na BMW. Disponível em: <http://www.bmw.pt/pt/topics/offers-andservices/personal-services/recycling.html>. Acesso em 07.06.2016.

BRAGA, Marcos da Costa (org.). O papel social do design gráfico: história, conceitos \& atuação profissional. São Paulo: Editora Senac, 2011.

IDEC. Em cinco anos, metade dos computadores apresentará algum defeito. Disponível em: <http://www.idec.org.br/consultas/testes-e-pesquisas/em-cinco-anos-metade-doscomputadores-apresentara-algum-defeito>. Acesso em 10.05.16.

KRIPPENDORFF, Klaus. Design centrado no ser humano: uma necessidade cultural. Revista Estudos em Design, Rio de Janeiro 8, 3: 87-98, 2000. Disponível em: $<$ http://periodicos.anhembi.br/arquivos/Hemeroteca/Periodicos_MO/Estudos_em_Desi gn/107170.pdf $>$. Acesso em 07.06.2016.

MANZINI, Ezio. Design para a inovação social e sustentabilidade: comunidades criativas, organizações colaborativas e novas redes projetuais. Rio de Janeiro: E-papers, 2008.

MARGOLIN, Victor; MARGOLIN, Sylvia. Um “modelo social” de design: questões de prática e pesquisa. in Revista Design em Foco, v. 1, n. 001, p. 42-48, Salvador:

Universidade do Estado da Bahia, 2004.

MINISTÉRIO DO MEIO AMBIENTE. Logística Reversa. Disponível em: $<$ http://www.mma.gov.br/cidades-sustentaveis/residuos-perigosos/logistica-reversa>. Acesso em 22.05.2016.

ONU. <https://nacoesunidas.org/>. Acesso em 07.06.2016.

PAPANEK, Victor. Design for the real world human ecology and social change. Chicago: Academy Chicago Publishers, $2^{\text {nd }}$ ed., 1971.

(1998).

. Arquitectura e design. Ecologia e ética. Lisboa: Edições 70, 2014 
REDIG, Joaquim. Design: Responsabilidade Social no Horário do Expediente. In: BRAGA, Marcos da Costa (org.). O papel social do design gráfico: história, conceitos \& atuação profissional. São Paulo: Editora Senac, 2011.

SEVCENKO, Nicolau. A corrida para o século XXI - No loop da montanha russa. São Paulo: Companhia das Letras, 2001.

STEP - SOLVING THE E-WASTE PROBLEM. Disponível em: <www.step-initiative.org>. Acesso em 07.06.2016. 